ARTICLE

\title{
Pathogenesis of chronic obstructive pulmonary disease: An African perspective
}

\author{
B Allwood, ${ }^{1} \mathrm{MB}$ BCh, DCH (SA), DA (SA), FCP (SA), MPH, Cert Pulmonology (SA), PhD; \\ G Calligaro, ${ }^{2}$ BSc (Hons), MB BCh, Dip PEC, FCP (SA), MMed, Cert Pulmonology (SA) \\ ${ }^{1}$ Division of Pulmonology, Department of Medicine, Faculty of Medicine and Health Sciences, Stellenbosch University and
Tygerberg Academic Hospital, Cape Town, South Africa
${ }^{2}$ Lung Infection and Immunity Unit, Division of Pulmonology and UCT Lung Institute, Department of Medicine, Faculty of Health Sciences,
Groote Schuur Hospital and University of Cape Town, South Africa
}

Corresponding author: B Allwood (brianallwood@sun.ac.za)

The importance of chronic obstructive pulmonary disease (COPD) as a global health problem cannot be overstated. According to the latest World Health Organization statistics (2005), 210 million people suffer from COPD worldwide, and 5\% of all deaths globally are estimated to be caused by this disease. This corresponds to $>3$ million deaths annually, of which $90 \%$ are thought to occur in low- and middle-income countries.

While cigarette smoking remains the major risk factor, and much of the increase in COPD is associated with projected increases in tobacco use, epidemiological studies have demonstrated that in the majority of patients in developing countries the aetiology of COPD is multifactorial.

This article summarises the epidemiology of and risk factors for COPD in Africa, including influences other than cigarette smoking that are important contributors to chronic irreversible airflow limitation in our setting.

S Afr Med J 2015;105(9):789. DOI:10.7196/SAMJnew.8424

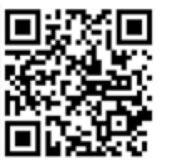

The importance of chronic obstructive pulmonary disease (COPD) as a global health problem cannot be overstated. According to the latest World Health Organization (WHO) statistics (2005), approximately 210 million people suffer from COPD worldwide, and $5 \%$ of all deaths globally are estimated to be caused by this disease. This corresponds to $>3$ million deaths annually, of which $90 \%$ are thought to occur in low- and middle-income countries. A projection published by the WHO Global Burden of Disease Project indicates that COPD will be the third leading cause of death globally by $2030 .{ }^{[1]}$ Much of this burden will be in the developing populations of Africa, Asia and the Indian subcontinent. As developing countries can ill afford the added economic burden of COPD, there is an urgent need to understand and address the risk factors for the development of COPD in these countries.

While cigarette smoking remains the major risk factor, and much of the increase in COPD is associated with projected increases in tobacco use, epidemiological studies have demonstrated that in the majority of patients in developing countries the aetiology of COPD is multifactorial. Research has suggested that a quarter to almost a half of all patients with COPD are non-smokers. ${ }^{[2]}$ Attributable fractions have been calculated for diverse influences such as environmental tobacco smoke exposure (passive smoking), smoke from biofuel combustion, exposure to dust, fumes and vapours, childhood illness, and previous tuberculosis (TB). Combinations of these risk factors are likely to be highly prevalent or even the rule in poor communities in developing countries, and may account for the greater frequency and severity of COPD in these settings.

In this article, we summarise the epidemiology of and risk factors for COPD in Africa, including influences other than cigarette smoking that are important contributors to chronic irreversible airflow limitation in our setting.

\section{Tobacco smoking}

Cigarette smoking remains the most well-documented and important cause of COPD. However, the old adage that 'only $15 \%$ of smokers will get COPD', and by implication the remaining $85 \%$ are immune to the effects of cigarette smoke, should be viewed with increasing scepticism. Susceptibility to the effects of smoke should rather be viewed as a continuous variable, not as an either/or phenomenon. Therefore, almost all smokers will develop reduced lung function if they smoke sufficient cigarettes over a sufficient period of time. ${ }^{[3]}$ While some smokers develop very severe COPD, and the rare smoker is unaffected, the majority of smokers lie between these two extremes. Possibly a more reliable figure, derived from a large Copenhagen cohort, is that after 25 years of smoking, $30-40 \%$ of smokers with normal baseline lung function will develop COPD, with $25 \%$ deemed to have clinically significant disease. ${ }^{[4]}$

Rather unsurprisingly, the chance of developing COPD increases with the number of cigarettes smoked. The adjusted hazard ratio has been reported to be 1.9 for smokers with a $<10$ pack-year history of smoking, and 8.8 for those with a $>50$ pack-year history of smoking. ${ }^{[5]}$ Consistent with this dose-response relationship, early cessation of smoking has been shown to dramatically reduce the chance of developing severe disease. ${ }^{[4]}$ However, the absence of clinical disease should not be viewed as reassuring, as emphysema on computed tomography (CT) imaging can be seen in $40 \%$ of smokers, with no evidence of abnormalities of lung function testing. ${ }^{[6]}$

Passive smoking, which frequently begins in early childhood, has also been confirmed as a risk factor for COPD. Similar to smoking, an exposure-response gradient exists, with greater exposure being associated with greater risk. ${ }^{[7]}$

Cannabis smoking and its relationship with COPD is more controversial and difficult to prove, as cannabis and tobacco are frequently smoked concurrently. Some studies suggest that heavy use ( $>20$ joint-years) is associated with airflow obstruction, but these findings are inconsistent. In a local study, $\mathrm{Jithoo}^{[8]}$ found cannabis use to be a strong predictor of chronic bronchitis, and concluded that the drug is a likely contributor to both chronic respiratory symptoms and possibly COPD, if not a sufficient cause in its own right. 
Airway inflammation with mucus hypersecretion (chronic bronchitis) as well as enlargement and destruction of the walls of the distal air spaces (emphysema) are the end results of cigarette smoking, and underlie the mechanisms of airflow obstruction observed in COPD. In a person with COPD, either chronic bronchitis or emphysema may predominate; however, both frequently coexist in varying proportions.

Globally, the attributable fraction of cigarette smoking towards COPD deaths varies by both gender and geographical region, with cigarettes being responsible for more deaths from COPD in developed nations and in males compared with developing nations and females. In developed nations, the attributable fraction is $77-84 \%$ for men and $61-62 \%$ for women, while the corresponding rates in developing nations are $45-49 \%$ and $12-20 \%$, respectively. ${ }^{[7]}$ In South Africa (SA), Groenewald et al. ${ }^{\left[{ }^{[]}\right.}$estimated the overall population-attributable fraction of COPD to smoking as $62 \%$ overall (69\% for men and $51 \%$ for women). However, the prevalence of smoking is not uniform across the entire population, with coloureds having the highest rates of smoking, followed by whites and blacks. ${ }^{[10]}$

From the abovementioned figures it is clear that cigarette smoking is not the only cause of COPD. Salvi and Barnes ${ }^{[2]}$ estimate that $25-45 \%$ of patients with COPD have never smoked. Ninety per cent of COPD deaths occur in low- and middle-income countries, and it is likely that non-smoking causes contribute to this excess burden of disease. ${ }^{[1]}$

\section{Biomass smoke exposure} Foremost among non-smoking causes of COPD is the use of biomass fuels for daily indoor cooking and heating. It is estimated that approximately 3 billion people worldwide are exposed to smoke from the burning of wood, dung, crop residue and other organic fuels. This represents $50 \%$ of all households and $90 \%$ of rural households, and it has been suggested that biomass exposure may be a more important global cause of COPD than cigarette smoking. ${ }^{[2]}$ The use of stoves and open fires indoors, with poor ventilation, produces high levels of pollutants, similar to tobacco smoke, and places primarily women and young children at risk. The WHO estimates that biomass exposure kills 2 million women and children, and that lung growth in young children may be particularly affected. ${ }^{[1]}$ The odds ratio for the development of COPD in women exposed to biomass has been estimated at 2.40 (95\% confidence interval (CI) 1.47 - 3.93). ${ }^{[11]}$

In $2007,20 \%$ of SA households were said to be exposed to indoor smoke, with marked variations between the different population groups. Biomass use in SA was estimated to account for $13.1 \%$ of COPD in men and $31.1 \%$ in women, and to be responsible for 2957 and 8920 disability-adjusted life-years (DALYs) in men and women, respectively. ${ }^{[12]}$

\section{Tuberculosis} development of COPD was previously controversial; however, several large population cross-sectional studies have confirmed the association, with some studies claiming that it is stronger than that for either smoking or biomass exposure. ${ }^{[13-16]}$ In an SA study, Jithoo ${ }^{[8]}$ found that the odds ratio of TB for mild and moderate COPD was 2.6 (95\% CI 1.5 - 4.6), while for severe and very severe disease is was 8.9 (95\% CI 4.2 - 18.9). Furthermore, it was found that almost $50 \%$ of adults $>40$ years of age with a history of previous TB had evidence of chronic airflow limitation. ${ }^{[8]}$

The mechanism of airflow obstruction, in what is increasingly being termed TB-associated obstructive pulmonary disease, remains uncertain; also whether this should be considered the same as smoking-related COPD or as a different phenotype with its own treatment, rate of decline and outcomes. We have found subtle but important physiological differences in these two conditions, implying a somewhat different pathogenesis of airflow limitation not accounted for by the presence of bronchiectasis. It is clear that a significant proportion of patients who airflow limitation, with varying degrees of disability. Considering the estimated 9 million annual cases of TB globally (330 000 in SA), the potential problem of chronic airflow limitation is immense and requires urgent further study. ${ }^{[17]}$
The association between $\mathrm{TB}$ and the later complete $\mathrm{TB}$ treatment have residual chronic

\section{HIV}

The lung is a major target organ for HIV, rendering it susceptible to a wide array of infectious and non-infectious complications. ${ }^{[18,19]}$ With the advent of early antiretroviral therapy (ART) and widespread antimicrobial prophylaxis, HIV-associated mortality ${ }^{[20,21]}$ and incidence of opportunistic and recurrent infections ${ }^{[22]}$ have been greatly reduced. In the developed world, this has resulted in a large-scale shift in the epidemiology of adult HIV-related pulmonary diseases. With a decrease in opportunistic infections and an increase in life expectancy, COPD has emerged as a potentially important non-infectious complication of HIV. ${ }^{[23]}$ Preliminary crosssectional studies have documented a high prevalence of COPD among HIV-infected individuals, and described an association with risk factors such as cigarette smoking, previous opportunistic infections, markers of HIV infection and ART use. ${ }^{[24-30]} \mathrm{A}$ few longitudinal studies have suggested that the magnitude of lung function decline in individuals with uncontrolled HIV infection exceeds that which is generally attributed to current smoking alone. ${ }^{[31]}$ Despite the high burden of HIV infection in sub-Saharan Africa, there is a paucity of data on lung function in HIV-infected individuals from this region: a study from Nigeria found significantly lower forced expiratory volume in 1 second $\left(\mathrm{FEV}_{1}\right)$ values and a higher incidence of COPD among HIV-positive compared with HIV-negative individuals, ${ }^{[30]}$ while an SA report of a relatively young, predominantly female and largely non-smoking cohort of treated HIV-infected individuals on ART found that irreversible airflow obstruction was present in $7 \%,{ }^{[24]}$ a higher figure than

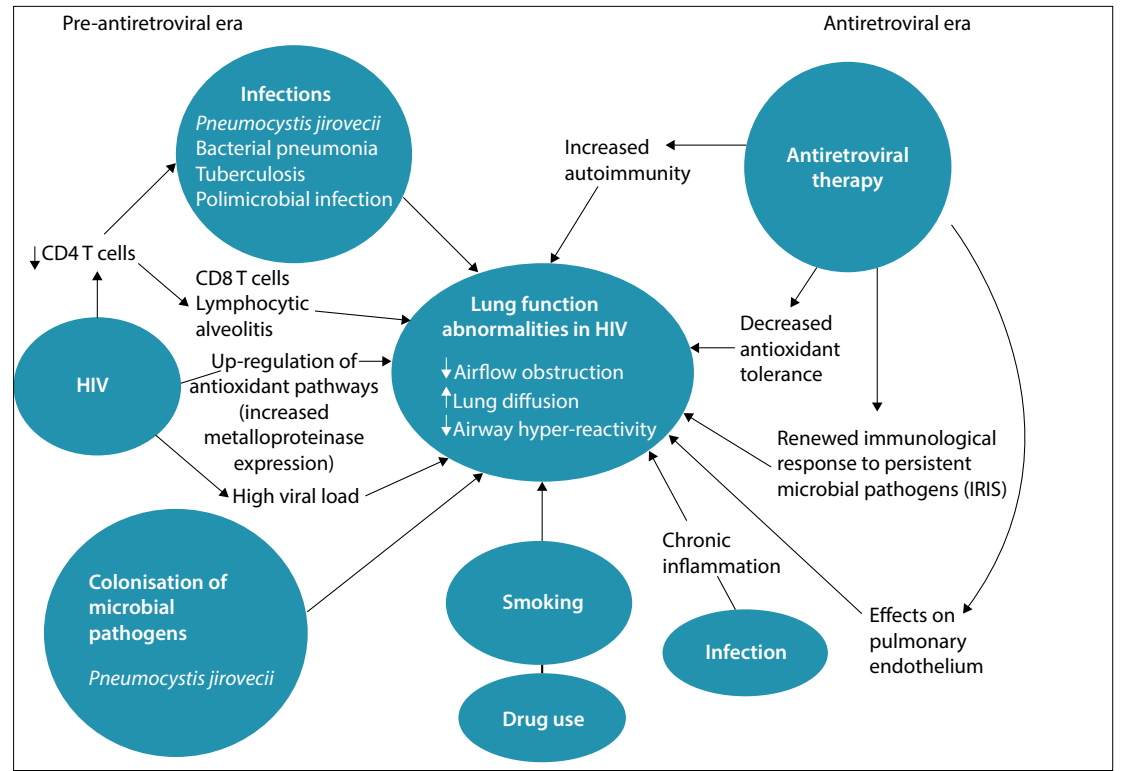

Fig. 1. Factors underlying the interaction between HIV and chronic lung disease. 
would be expected in an HIV-uninfected population with similar demographics.

The mechanisms behind HIV-associated COPD are unknown, but may result from the HIV infection, the effect of long-term ART and immune reconstitution, the development of autoimmunity, or the effects of repeated pulmonary infections, or may simply be due to living with HIV for an extended period of time (Fig. 1). These interactions have major public health implications - the direct and indirect effects of HIV infection, together with the projected increases in tobacco use, biomass fuel exposure, and high rates of childhood infections, have the potential to create a 'perfect storm' of chronic pulmonary disability in Africa. ${ }^{[32]}$

\section{Occupational exposures}

There is accumulating evidence that COPD is caused by occupational exposures to respirable dusts, smoke, vapours and fumes. The American Thoracic Society's consensus statement suggests that between $10 \%$ and $20 \%$ of COPD is attributable to workplace exposures. ${ }^{[33]}$

In SA, much epidemiological work has been done on the association between respirable silica dust and airflow obstruction (independent of radiological silicosis) in underground gold miners. ${ }^{[34]}$ In one study, the contribution of $\mathrm{FEV}_{1}$ loss due to silica was estimated at about half that of smoking 30 cigarettes a day for 30 years. ${ }^{[35]}$ Although this effect is observed even in non-smokers, smoking and silica exposure are multiplicative, potentiating the development of and mortality from COPD ${ }^{[36]}$ Lastly, workers exposed to silica dust are at increased risk of developing TB, even in the absence of silicosis. ${ }^{[3]}$ As described above, residual damage from treated $\mathrm{TB}$ is also associated with airflow obstruction and chronic respiratory symptoms.

The association between occupational exposures to dust and chemicals and COPD has been demonstrated in studies of workers employed in other industries in Africa. ${ }^{[37-41]}$ These occupational exposures include (but are not limited to) inorganic dust, cadmium, coal, organic dust, cotton, grain, diesel fumes, and welding. In a hospital-based case control study from KwaZulu-Natal, self-reported occupational exposures to biological dust or gas and fumes were associated with a two-fold increased odds of developing COPD, after adjustment for smoking and previous TB. ${ }^{[42]}$

\section{Intra-uterine environment, pre- maturity and childhood respiratory infections}

COPD may originate in childhood, or even in utero. Low-birthweight babies or those whose mothers smoked during pregnancy have reduced lung function. ${ }^{[43,44]}$ Other antenatal effects that may negatively affect fetal lung development include maternal hypertension or pre-eclampsia, diabetes, medication $\mathrm{use}^{[45]}$ and exposure to air pollution. ${ }^{[46]}$

The effects of perinatal events, such as premature birth on lung function, are well documented. ${ }^{[4]}$ Preterm infants have an increased risk of impaired lung function in infancy, childhood and adulthood, and an increased risk of respiratory illness. Long-term lung injury is caused by arrest of structural lung development at an immature stage (bronchopulmonary dysplasia), and is exacerbated by the use of mechanical ventilation and high-concentration supplemental oxygen in infancy. ${ }^{[48,49]}$

Severe pulmonary viral and bacterial infections in childhood have been shown to be associated with reduced lung function and obstructive spirometry in adult life. ${ }^{[50]}$ Childhood infection damages a vulnerable lung undergoing rapid postnatal growth, and may also make it increasingly susceptible to additional noxious agents such as cigarette smoke or indoor air pollution. Postinfective bronchiolitis obliterans and bronchiectasis are common sequelae that cause chronic airflow limitation in survivors of severe childhood respiratory infection.

\section{Conclusion}

In the developing world, the pathogenesis of COPD is likely to be multifactorial. Colliding epidemics of TB, cigarette smoking, pulmonary infection and HIV threaten to greatly increase the burden of chronic lung disease in these regions. ${ }^{[32]}$ There is therefore an urgent need to study the influences and interaction between these putative causative factors, particularly in Africa.

\section{References}

1. World Health Organization. Chronic obstructive pulmonary disease (COPD). Fact Sheet. 2013. http:// www.who.int/mediacentre/factsheets/fs315/en/index.html (accessed 31 July 2015).

2. Salvi SS, Barnes P. Chronic obstructive pulmonary disease in non-smokers. Lancet 2009;374(9691):733-743. [http://dx.doi.org/10.1016/S0140-6736(09)61303-9]

2009;374(9691):733-743. [http://dx.doi.org/10.1016/S0140-6736(09)61303-9]
Rennard SI, Vestbo J. COPD: The dangerous underestimate of 15\%. Lancet 2006;367(9518):1216-1219.

3. Rennard SI, Vestbo J. COPD: The dangerous underestimate of 15\%. Lancet 2006;367(9518):1216-1219.
4. Løkke A, Lange P, Scharling H, Fabricius P, Vestbo J. Developing COPD: A 25 year follow up study of the general population. Thorax 2006;61(11):935-939.

5. Van Durme YMT, Verhamme KMC, Stijnen T, et al. Prevalence, incidence, and lifetime risk for the development of COPD in the elderly: The Rotterdam study. Chest 2009;135(2):368-377. [http://dx.doi. org/10.1378/chest.08-0684]

6. Mastora I, Remy-Jardin M, Sobaszek A, Boulenguez C, Remy J, Edme JL. Thin-section CT finding in 250 volunteers: Assessment of the relationship of CT findings with smoking history and pulmonary function test results. Radiology 2001;218(3):695-702.

7. Eisner MD, Anthonisen N, Coultas D, et al. An official American Thoracic Society public policy statement: Novel risk factors and the global burden of chronic obstructive pulmonary disease. Am J Respir Crit Care Med 2010;182:693-718. [http://dx.doi.org/10.1164/rccm.200811-1757ST]

8. Jithoo A. Respiratory Symptoms and Chronic Obstructive Pulmonary Ddisease. Prevalence and Risk

Jithoo A. Respiratory Symptoms and Chronic Obstructive Pulmonary Ddisease. Prevalence and Risk
Factor in a Predominantly Low-income Urban Area of Cape Town, South Africa. PhD thesis. Cape Factor in a Predominantly Low-income Urb
Town: University of Cape Town, 2006:1-284.

9. Groenewald P, Vos T, Norman R, et al. Estimating the burden of disease attributable to smoking in
G South Africa in 2000. S Afr Med J 2007;97(8):674.
Sout

10. Sitas F, Egger S, Bradshaw D, et al. Differences among the coloured, white, black, and other South African populations in smoking-attributed mortality at ages 35-74 years: A case-control study of 481,640 deaths. Lancet 2013;382(9893):685-693. [http://dx.doi.org/10.1016/S0140-6736(13)61610-4]

11. Po JYT, FitzGerald JM, Carlsten C. Respiratory disease associated with solid biomass fuel exposure in rural women and children: Systematic review and meta-analysis. Thorax 2011;66(3):232-239. [http:// dx.doi.org/10.1136/thx.2010.147884]

2. Norman R, Barnes B, Mathee A, Bradshaw D. Estimating the burden of disease attributable to indoo air pollution from household use of solid fuels in South Africa in 2000. S Afr Med J 2007;97(8):764-771.

13. Menezes AMB, Perez-Padilla R, Jardim JB, et al. Chronic obstructive pulmonary disease in five Latin American cities (the PLATINO study): A prevalence study. Lancet 2005;366(9500): 1875-1881.

14. Caballero A, Torres-Duque CA, Jaramillo C, et al. Prevalence of COPD in five Colombian cities situated at low, medium, and high altitude (PREPOCOL Study). Chest 2008;133(2):343-349.

15. Lam KB, Jiang CQ, Jordan RE, et al. Prior TB, smoking, and airflow obstruction : A cross-sectional Lam KB, Jiang CQ, Jordan RE, et al. Prior TB, smoking, and airflow obstruction : A cross-sectional
analysis of the Guangzhou Biobank Cohort Study. Chest 2010;137(3):593-600. [http://dx.doi. analysis of the Guangzhou
org $/ 10.1378 /$ chest.09-1435]

16. Idolor LF, de Guia TS, Francisco NA, et al. Burden of obstructive lung disease in a rural setting in the Philippines. Respirology 2011;16(7):1111-1118. [http://dx.doi.org/10.1111/j.1440-1843.2011.02027.x] 17. World Health Organization. Tuberculosis country profiles. http://www.who.int/tb/country/data/ profiles/en/ (accessed 31 July 2015).

18. Morris A, Crothers K, Beck JM, Huang L. An official ATS workshop report: Emerging issues and current controversies in HIV-associated pulmonary diseases. Proc Am Thorac Soc 2011;8(1):17-26. [http://dx.doi.org/10.1513/pats.2009-047WS]

9. Kanmogne GD. Noninfectious pulmonary complications of HIV/AIDS. Curr Opin Pulm Med 2005;11(3):208-212

20. Gortmaker SL, Hughes M, Cervia J, et al. Effect of combination therapy including protease inhibitors on mortality among children and adolescents infected with HIV-1. N Engl J Med 2001;345(21):15221528 .

21. Violari A, Cotton MF, Gibb DM, et al. Early antiretroviral therapy and mortality among HIV-infected infants. N Engl J Med 2008;359(21):2233-2244.

22. Nesheim SR, Kapogiannis BG, Soe MM, et al. Trends in opportunistic infections in the pre- and post-highly active antiretroviral therapy eras among HIV-infected children in the Perinatal AIDS Collaborative Transmission Study, 1986-2004. Pediatrics 2007;120(1):100-109.

23. Hull MW, Phillips P, Montaner JSG. Changing global epidemiology of pulmonary manifestations of HIV/AIDS. Chest 2008;134(6):1287-1298. [http://dx.doi.org/10.1378/chest.08-0364]

24. Calligaro G, Bateman ED, Rom WN, Dheda K, van Zyl-Smit RN, Weiden M. Respiratory symptoms and pulmonary function abnormalities in HIV-infected patients on antiretroviral therapy in a high tuberculosis burden country. American Thoracic Society 2011 International Conference, Denver, Colorado, 13 - 18 May 2011. Abstract A6262-A.

25. Cui Q, Carruthers S, McIvor A, Smaill F, Thabane L, Smieja M. Effect of smoking on lung function, respiratory symptoms and respiratory diseases amongst HIV-positive subjects: A cross-sectional study. AIDS Res Ther 2010;7:6. [http://dx.doi.org/10.1186/1742-6405-7-6]

26. Drummond MB, Kirk GD, Astemborski J, et al. Association between obstructive lung disease and markers of HIV infection in a high-risk cohort. Thorax 2012;67(4):309-314. [http://dx.doi. and markers of HIV infection in a
org/10.1136/thoraxjnl-2011-200702]

27. George MP, Kannass M, Huang L, Sciurba FC, Morris A. Respiratory symptoms and airway obstruction in HIV-infected subjects in the HAART era. PLoS One 2009;4(7):e6328. [http://dx.doi. org/10.1371/journal.pone.0006328]

28. Gingo MR, George MP, Kessinger CJ, et al. Pulmonary function abnormalities in HIV-infected patients during the current antiretroviral therapy era. Am J Respir Crit Care Med 2010;182(6):790-796. [http:// dx.doi.org/10.1164/rccm.200912-1858OC]

29. Hirani A, Cavallazzi R, Vasu T, et al. Prevalence of obstructive lung disease in HIV population: A cros sectional study. Respir Med 2011;105(11):1655-1661. [http://dx.doi.org/10.1016/j.rmed.2011.05.009] 30. Onyedum CC, Chukwuka JC, Onwubere BJC, Ulasi II, Onwuekwe IO. Respiratory symptoms and ventilatory function tests in Nigerians with HIV infection. Afr Health Sci 2010;10(2):130-137.

31. Anthonisen NR, Connett JE, Murray RP. Smoking and lung function of Lung Health Study participants after 11 years. Am J Respir Crit Care Med 2002;166(5):675-679. 
32. Van Zyl-Smit RN, Pai M, Yew WW, et al. Global lung health: The colliding epidemics of tuberculosis, tobacco smoking, HIV and COPD. Eur Respir J 2010;35(1):27-33. [http://dx.doi. tuberculosis, tobacco smoking,
org/10.1183/09031936.00072909]

33. American Thoracic Society Committee of the Scientific Assembly on Environmental and American Thoracic Society Committee of the Scientific Assembly on Environmental and
Occupational Health. Adverse effects of crystalline silica exposure. Am J Respir Crit Care Med Occupational Health

34. Hnizdo E. Loss of lung function associated with exposure to silica dust and with smoking and its relation to disability and mortality in South African gold miners. Br J Ind Med 1992;49(7):472 479.

35. Cowie RL, Mabena SK. Silicosis, chronic airflow limitation, and chronic bronchitis in South African gold miners. Am Rev Respir Dis 1991;143(1):80-84.

36. Hnizdo E. Combined effect of silica dust and tobacco smoking on mortality from chronic obstructive lung disease in gold miners. Br J Ind Med 1990;47(10):656-664

37. Ballal SG. Respiratory symptoms and occupational bronchitis in chromite ore miners, Sudan. I Trop Med Hyg 1986;89(5):223-228.

38. Laraqui $\mathrm{CH}$, Laraqui $\mathrm{O}$, Rahhali A, et al. Prevalence of respiratory problems in workers at two manufacturing centers of ready-made concrete in Morocco. Int J Tuberc Lung Dis 2001;5(11):1051-1058

39. Laraqui $\mathrm{CH}$, Yazidi AA, Rahhali TA, et al. The prevalence of respiratory symptoms and immediate hypersensitivity reactions in a population exposed to flour and cereal dust in five flour mills in
hate hypersensitivity reactions in a population exposed
Morocco. Int I Tuberc Lung Dis 2003;7(4):382-389.

40. Mustafa KY, Lakha AS, Milla MH, Dahoma U. Byssinosis, respiratory symptoms and spirometric lung

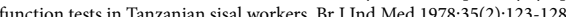

41. Yach D, Myers J, Bradshaw D, Benatar SR. A respiratory epidemiologic survey of grain mill workers in Cape Town, South Africa. Am Rev Respir Dis 1985;131(4):505-510.

42. Govender N, Lalloo UG, Naidoo RN. Occupational exposures and chronic obstructive pulmonary disease: A hospital based case-control study. Thorax 2011;66(7):597-601. [http://dx.doi.org/10.1136/ thx.2010.149468]

43. Lødrup Carlsen KC, Jaakkola JJ, Nafstad P, Carlsen KH. In utero exposure to cigarette smoking influences lung function at birth. Eur Respir J 1997;10(8):1774-1779.

44. Stick SM, Burton PR, Gurrin L, Sly PD, LeSouëf PN. Effects of maternal smoking during pregnancy and a family history of asthma on respiratory function in newborn infants. Lancet 1996;348(9034):1060-1064. 45. Rusconi F, Galassi C, Forastiere F, et al. Maternal complications and procedures in pregnancy and at birth and wheezing phenotypes in children. Am J Respir Crit Care Med 2007;175(1):16-21.

46. Latzin P, Röösli M, Huss A, Kuehni CE, Frey U. Air pollution during pregnancy and lung function in newborns: A birth cohort study. Eur Respir J 2009;33(3):594-603. [http://dx.doi. org/10.1183/09031936.00084008

47. Baraldi E, Filippone M. Chronic lung disease after premature birth. N Engl J Med 2007;357(19):19461955.

48. Gross SI, Iannuzzi DM, Kveselis DA, Anbar RD. Effect of preterm birth on pulmonary function at school age: A prospective controlled study. J Pediatr 1998;133(2):188-192.

49. Jones M. Effect of preterm birth on airway function and lung growth. Paediatr Respir Rev 2009;10(Suppl 1):9-11. [http://dx.doi.org/10.1016/S1526-0542(09)70005-3]

50. Samet JM, Tager IB, Speizer FE. The relationship between respiratory illness in childhood and chronic air-flow obstruction in adulthood. Am Rev Respir Dis 1983;127(4):508-523. 